\title{
Consumer behaviour in the Thai Internet Service Providers
}

\author{
Paramaporn Thaichon \\ S P Jain School of Global Management, Australia
}

\begin{abstract}
This research aims to explore the characteristics and perceptions of Internet Service Provider' customers in order to provide a general picture of ISP subscribers and enable more customer-focused market strategies. Data was obtained from 2,059 Internet users in all the regions of Thailand via an online survey. The result shows that no noticeable differences were found among age groups in terms of the reasons for their switching. In contrast, customers with higher income were more likely to choose poor Internet service performance as the main reason to switch. Therefore, it is likely that age did not contribute to the respondents' motivation for switching while income was an important factor in switching behaviour. Additionally, high price and fewer promotional packages are popular reasons for switching among groups with the lowest levels of household income.Practical implications that can be drawn from this research will form a foundation for service providers in the home ISP to develop new retention strategies. As a result, ISPs will be able to reduce the current issues relating to customer switching in the home ISP.
\end{abstract}

Key words: Internet user, Internet usage pattern, Segmentation,Consumer behaviour, Internet Service Providers (ISP).

\section{Introduction}

Thailand is ranked third in south-east Asia for residential Internet usage, with an estimated 17,483,000 Internet users in 2009 (CIA, 2013) and more than 24 million Internet users in 2012 (IWS, 2013). The number in 2012 represented more than onethird of the Thai population. The competition in Thailand among residential Internet service providers is intense. Currently there are 3 majors ISPs and 16 smaller ones across the country. In this highly competitive market, the churn rate of users was approximately 12\% in 2009 (Thaichon, Lobo, and Mitsis, 2014). This scenario poses huge challenges to ISPs in Thailand, especially in the area of customers' repurchase intentions.

The Internet had its birth in the early 1960s, after the US Department of Defence realised the need for a decentralised computer network that could provide the Pentagon with a command and control communications system in the event of contingencies (Simsim, 2011). The Internet alsoprovided a robust and fault-tolerant 
computer network for the United States military (Teo and Tan, 1998). This pioneering network was known as the Advanced Research Projects Agency network or ARPANET, and slowly appeared in university and government research laboratories owing to its several advantages (Simsim, 2011). These advantages included its ability to let individuals exchange electronic mail, tap into remote databases and operate supercomputers remotely (Teo and Tan, 1998).

Teo and Tan (1998) state that the greatest improvement was the communications protocol that gave the Internet its name - "the Internet Protocol" - since it allowed numerous computer networks to link up and act as one. Further developments led to the commercialisation of the Internet as an international network in the mid-1990s (Simsim, 2011). By the end of September 2009, the estimated number of Internet users around the world reached 1.733 billion, indicating that the Internet was being used by more than $25 \%$ of the world's population and growing on a daily basis (Simsim, 2011). Trkman, Jerman-Blažič, and Turk (2008) assert that economic growth, competition, educational level, English proficiency, level of democracy, and social networks are positively related to an increase in the number of ISPs around the world.

Internet usage is growing across the globe. In the 2010s, electronic communications became key to many people's daily lives, and the Internet was also being regularly utilised for entertainment, commerce and business activities (Wahab, Zahari, Momani, and Nor, 2011). Butt and de Run (2009) state that rapid growth in telecommunications technology can improve economic development by providing employment, improving business efficiency and contributing towards international investments. Magin, Algesheimer, Huber, and Herrmann (2003) point out that an ISP provides both $\mathrm{B} 2 \mathrm{~B}$ and $\mathrm{B} 2 \mathrm{C}$ access to the Internet, which is a critical source of communications and it is linked to related services, such as media content, website building or virtual hosting (Magin et al., 2003).

\section{The Internet services market in Thailand}

The Internet was introduced to Thailand in 1991, however it was only in 1999 that Internet usage rates experienced major growth (NECTEC, 2014). Since 2000, significant investment in education has resulted in greater knowledge and higher qualifications among Thai people (Srihirun, 2011). This partly explains the massive development of the telecommunications industry in Thailand (Srihirun, 2011). During the period of 2000 to 2010, the number of Internet users grew by $30 \%$ each year (Srihirun, 2011). Similarly, the National Electronics and Computer Technology Centre, (NECTEC, 2014) reported 84.68\% growth from 2005 to 2009. These figures show that telecommunications play an important part in Thailand's economy, and this is especially true for broadband, which is projected to grow annually at $23 \%$ (Srihirun, 2011).

Internet usage in Thailand grew due to the uptake of entertainment-based Internet applications by young users. In 2009, the greatest number of Internet users, 69.14\%, used the Internet for entertainment and gaming. The second largest group, $27.4 \%$ of users, used the Internet for social and business affairs. Interestingly only $1.75 \%$ of users visited government websites and just $1.71 \%$ were interested in educational content (NECTEC, 2014). 


\section{Consumer buyer behaviour in Thailand}

Consumer behaviour is different across the world because each country has unique social traits and demographic characteristics, as well as differing economic challenges (Kotler, 2003; Schiffman and Kanuk, 1997). Marketers need to understand consumer behaviour in particular geographic areas where a business operates in order to undertake effective marketing activities (Kotler, 2003). According to Schiffman and Kanuk (1997), understanding consumer behaviour can help to explain how and why consumers make decisions to purchase certain products and services.

A study of Thai consumer buyer behaviour by Thananuraksakul (2007) reveals that Thai consumers' purchase decisions are determined by both extrinsic (i.e. service quality, quantity, price, promotion, and availability) and intrinsic factors, such as consumer self-image, self-respect and social-respect, demographics and Thai culture (Silayoi and Speece, 2007). Extrinsic factors are considered important to consumers in a big city, for example, Bangkok. This is because markets in big cities tend to be highly competitive with a great number of companies offering undifferentiated services and targeting the same segments (Thananuraksakul, 2007). Songpradit (2005) states that a salesperson's attitude and behaviour are positively related to a Thai consumer's purchase decisions. However, when it comes to mobile phone and Internet services in Thailand, salespeople have less of an impact on the consumer purchasing decision. In addition, Thai consumers, especially those who have low to middle income, tend to purchase services that give them the best value, as weighed up in cost-benefit terms, regardless of the reputation of the service provider (Thananuraksakul, 2007). Many Thai people also make purchase decision designed to enhance their self-image, self-respect, social-respect and sense of social belonging (Sukato and Elsey, 2009). As a result, they spend more time and money purchasing services pertaining to their health, beauty and lifestyle (Sukato and Elsey, 2009).

In terms of customer lifestyle, Feeny and Vongpatanasin (1996) note that Thai consumers in larger towns spend more time in shopping malls and department stores, using them as a meeting place with friends and family. Lekagul (2002) also reports Thai consumers frequently go to shopping malls for recreation activities, such as window shopping, karaoke, seeing a film and bowling. Recent trends show that Thai companies and consumers are becoming more conscious regarding environmental issues (Sukato and Elsey, 2009). As a result, they show preferences for services offered by companies that are environmentally friendly. However, Sukato and Elsey (2009) state that while Thai consumers may be interested in "green" products, they are not willing to compromise on price and safety.

Another factor that affects Thai consumers' decision making is their culture(Silayoi and Speece, 2007; Webster, 2000). In general, Thai culture is classified as being collectivist, which means that Thai people are influenced by friends, family and social groups to which they belong (Sukato and Elsey, 2009). For example, young people in similar age groups tend to prefer similar style, food and fashion (Lekagul, 2002). In terms of family influence, Silayoi and Speece (2007) point out that the father is most likely to pay the household bills, whereas mothers tend to make the final decision at the point of purchase. Also, wives in Thailand tend to have strong influence over their husbands' decision-making (Webster, 2000). It is also common for Thai children to 
have a say in purchasing decisions when the household service relates to them (Webster, 2000).

In summary, the factors that influence Thai consumer behaviour are quality, price, brand, packaging, advertising, promotion, the attending salesperson, distribution, consumer attitudes towards the service, self-image and normative influences (i.e. spouse, friends, family and colleague). It is important that marketers understand these factors in order to develop the most effective strategy for long-term customer retention.

\section{Method}

\section{The study sample}

To test the hypotheses, an online survey was designed and conducted in all regions of Thailand. Thailand is ranked third in South East Asia by way of residential Internet usage with an estimated 17,483,000 Internet users in 2009 (CIA, 2013) and over 24 million Internet users in 2012 (IWS, 2013). The number in 2012 represented over one-third of the Thai population. The competition in Thailand among residential Internet service providers is intense. Currently there are three majors ISPs and sixteen smaller ones across the country (Thaichon and Quach, 2013). In this highly competitive market, the churn rate of Internet users was approximately $12 \%$ in 2009 (Thaichon, Lobo, and Mitsis, 2012). This scenario, therefore, poses huge challenges to ISPs especially in the area of customers' repurchase intention.

\section{Data collection}

Data was collected from residential Internet users in Thailand. A selective customer database of three well-established ISPs in Thailand were utilised as the sampling frame. The chosen corporations are the dominant players in the Internet services market in Thailand with nationwide coverage, and holds more than 90\% market share in total. This database included customers throughout Thailand who were not locked into any fixed term contract with the ISPs. Therefore, they were free to act as they desired, and their behavioural intentions could more accurately be investigated. It was a requirement that the participants were over 18 years of age and they should have used home Internet services. The survey instrument was administered online using the university's Opinio platform. The web link of the online survey was relayed to households in the sampling frame. The university's Opinio platform was kept live for a period of three months. A total of 8000 surveys were distributed in all geographical regions of Thailand.The final usable sample size was 2059 .

\section{Details of Internet services used}

Using frequency and descriptive statistics in SPSS, the details of respondents' Internet services used are analysed and discussed in the following sections. 


\section{Switching experience}

The results show that 61.5 per cent of the total respondents (1267 respondents) had used one or more other Internet service providers in the past. This indicates that 38.5 per cent of respondents (792 respondents) did not have any switching experience.

\section{Reasons for switching}

In term of reasons for switching service providers, the most common reason given was poor network performance (43.9 per cent or 556 respondents), followed by low quality customer service (43.1 per cent or 546 respondents). The results show that 37.4 per cent (474 respondents) of the 1267 respondents who switched from other ISPs did so because of lack of promotional packages. 24.8 per cent (314 respondents) switched because they claimed that the previous ISP's service was too expensive and 23.7 per cent (300 respondents) mentioned one or more other reasons for switching, for example poor aftersales service, insecure payment methods and threats of privacy violation.

\section{Frequency of Internet use}

The results show that a majority of respondents (73.3 per cent or 1509 respondents) used the Internet twice or more every day. 20.9 per cent (431 respondents) of the total respondents used the Internet once a day. Of those who used the Internet less frequently than once a day, 0.9 per cent (18 respondents) used the Internet once every two days, 0.4 per cent ( 8 respondents) used the Internet once every five days and 4.5 per cent (93 respondents) used the Internet once every week or less frequently.

\section{Internet usage time}

In terms of weekly time allocation for online activities, nearly half of the respondents (48.5 per cent or 998 respondents) spent more than 30 hours on the Internet each week. 3.7 per cent ( 76 respondents) spent less than 2 hours on the Internet each week. 24.9 per cent (512 respondents) spent between 2 and 9 hours online per week, 14.9 per cent (307 respondents) spent between 10 and 19 hours on the Internet each week, and 8.1 per cent (166 respondents) spent between 20 and 29 hours on the Internet every week. A recent report reveals that the average time a person spends on the Internet is approximately 20 hours (Nielson, 2013), which is relatively consistent with the finding of this study. However, it is noticeable that almost half of the respondents in this study spent more than 30 hours on the Internet. This suggests that people tend to rely heavily on the Internet, making it a significant aspect of modern life.

\section{Number of people in a household}

5.7 per cent (118 respondents) of the total respondents stated there was only one person in their household. 19.2 per cent (396 respondents) lived in a two-person household, 19.4 per cent (399 respondents) stated that there were three people in their household, 27.1 per cent (557 respondents) said their household comprised four people and 28.6 per cent (396 respondents) reported there were five or more people in their household. 


\section{Number of people using the Internet in a household}

Although half of the respondents lived in four or five person households, a large proportion (35.3 per cent or 727 respondents) reported that just two people used the Internet in their household. 12.1 per cent (250 respondents) said only one person in their household accessed the Internet. For 25.4 per cent of respondents (522 respondents) three people used the Internet in their house, 17.4 per cent (359 respondents) recorded four people in their house using the Internet, while 9.8 per cent (201 respondents selected five or more people).

\section{Types of Internet connection}

Broadband Internet was the most popular Internet connection with 59.1 per cent (1217 respondents) using this mode. Wireless USB Internet was the next most popular mode, being used by 24 per cent (494 respondents). Other Internet connection types were significantly less popular than these two modes. Only 5.2 per cent (107 respondents) used a dialup Internet connection, 5 per cent (103 respondents) used a lease line Internet connection and 6.7 per cent (138 respondents) used another type of Internet connection, for example fibre optics.

\section{Home Internet speed}

More than two-thirds of respondents (73.7 per cent or 1518 respondents) stated that their Internet speed ranged from $1.6 \mathrm{mbps}$ to $20 \mathrm{mbps}$ which is considered to be medium speed. 16.7 per cent (343 respondents) claimed that their Internet speed was between $512 \mathrm{kbps}$ and $1.5 \mathrm{mbps}$ which is considered to be lower speed. Internet speed for 1.7 per cent (36 respondents) of total respondents was lower than $512 \mathrm{kbps}$. The category of higher speed, i.e. between 21 mbps to 30 mbps was experienced by 1.7 per cent (36 respondents) and 3.1 per cent (64 respondents) selected Internet speed faster than 30 mbps. 3 per cent (62 respondents) were not sure about their Internet speed.

\section{Internet expenditure per month}

Nearly half of all respondents (48.1 per cent or 991 respondents) spent between 601 and 900 baht on Internet services per month. 20.1 per cent (414 respondents) spent slightly less on Internet services (between 301 and 600 baht) monthly. 2.2 per cent of respondents (46 respondents) spent less than 300 baht per month, while of the higher spenders, 12.7 per cent (262 respondents) spent between 901 and 1200 baht per month and 12.2 per cent (251 respondents) spent 1200 baht or more per month for Internet services. 4.6 per cent (95 respondents) were not sure about their expenditure for Internet services.

\section{Additional descriptive statistics}

In order to provide a generic situation of the interrelations between two variables, as well as to detect interactions between them, cross tabulation was employed. Cross tabulation displays a joint frequency distribution of two or more categoricalvariables (Michael, 2001). The distribution of cases by their values constitutes contingency table analysis and is among the most common analysis methods in survey research 
(Michael, 2001). In some cases, the analysis can be assisted by the chi square statistics $\left(\lambda^{2}\right)$ to determine whether variables are statistically independent or related. If a dependency between variables is confirmed, other indicators, for example Cramer's $\mathrm{V}$ and gamma, can be used to measure the strength of association between the variables. Cramer's V values range from 0 (showing no association between the variables) to 1 (indicating complete association).

\section{Switching experience versus age}

The number of respondents who switched from other ISPs was slightly higher than the number of who had not signed up with any other providers previously. Respondents in the 18-28 age group had less switching experience as compared to other groups. Although chi-square statistics were significant at $\mathrm{p}$ value $<0.05$, Cramer's $\mathrm{V}$ value was 0.074 indicating that the relationship between age and switching experience was weak (Table 1).

Table 1: Switching Experience versus Age

\begin{tabular}{|c|c|c|c|c|c|c|c|}
\hline & \multicolumn{4}{|c|}{ Age group } & \multirow[t]{2}{*}{ Total } \\
\hline & & & $18-28$ & $29-38$ & $39-49$ & $\begin{array}{c}50 \text { and } \\
\text { above }\end{array}$ & \\
\hline \multirow{6}{*}{$\begin{array}{l}\text { Previous } \\
\text { experience } \\
\text { with other } \\
\text { ISPs }\end{array}$} & \multirow{4}{*}{ Yes } & Count & 259 & 500 & 315 & 193 & 1267 \\
\hline & & $\begin{array}{l}\% \text { within Previous experience } \\
\text { with other ISP }\end{array}$ & $20.4 \%$ & $39.5 \%$ & $24.9 \%$ & $15.2 \%$ & $100.0 \%$ \\
\hline & & $\%$ within Age group & $55.7 \%$ & $62.7 \%$ & $61.8 \%$ & $67.2 \%$ & $61.5 \%$ \\
\hline & & Count & 206 & 297 & 195 & 94 & 792 \\
\hline & \multirow[t]{2}{*}{ No } & $\begin{array}{l}\% \text { within Previous experience } \\
\text { with other ISP }\end{array}$ & $26.0 \%$ & $37.5 \%$ & $24.6 \%$ & $11.9 \%$ & $100.0 \%$ \\
\hline & & $\%$ within Age group & $44.3 \%$ & $37.3 \%$ & $38.2 \%$ & $32.8 \%$ & $38.5 \%$ \\
\hline \multirow{3}{*}{ Total } & & Count & 465 & 797 & 510 & $\begin{array}{c}4.6 \% \\
287\end{array}$ & $\begin{array}{c}38.5 \% \\
2059\end{array}$ \\
\hline & & $\begin{array}{l}\% \text { within Previous experience } \\
\text { with other ISP }\end{array}$ & $22.6 \%$ & $38.7 \%$ & $24.8 \%$ & $13.9 \%$ & $100.0 \%$ \\
\hline & & $\%$ within Age group & $100.0 \%$ & $100.0 \%$ & $100.0 \%$ & $100.0 \%$ & $100.0 \%$ \\
\hline
\end{tabular}

Note: Chi-square $=11.144, \mathrm{df}=3, \mathrm{p}=0.011$, Cramer's V $=0.074$.

\section{Switching experience versus household income}

Table 2 depicts the relationship between monthly household income and switching experience. Except for the group with household income under 5,000 baht, it appears that the higher the household income of respondents, the more likely they were to change service providers. For example, approximately 70 per cent of respondents with a household income of 100,000 baht or more had previously purchased from other service providers. Chi square statistics was significant at $\mathrm{p}<0.001$ and Cramer's V value was 0.129 , demonstrating a moderately weak relationship between these variables. In other words, income may be related to the switching behaviour of an ISP's customers. 
Table 2: Switching Experience versus Household Income

\begin{tabular}{|c|c|c|c|c|c|c|c|c|c|}
\hline & \multicolumn{6}{|c|}{ Household monthly income } & \multirow[t]{3}{*}{ Total } \\
\hline & & & Under & $5,000-$ & 10,001 & 30,001 & $50,001-$ & Over & \\
\hline & & & 5,000 & 10,000 & 30,000 & 50,000 & 100,000 & 100,000 & \\
\hline \multirow{8}{*}{$\begin{array}{l}\text { Previous } \\
\text { experience } \\
\text { with other } \\
\text { ISPs }\end{array}$} & \multirow{8}{*}{ Yes } & Count & 18 & 40 & 297 & 274 & 334 & 304 & 1267 \\
\hline & & $\%$ within Previous & & & & & & & \\
\hline & & $\begin{array}{l}\text { experience with } \\
\text { other ISP }\end{array}$ & $1.4 \%$ & $3.2 \%$ & $23.4 \%$ & $21.6 \%$ & $26.4 \%$ & $24.0 \%$ & $100.0 \%$ \\
\hline & & $\begin{array}{l}\% \text { within Household } \\
\text { monthly income }\end{array}$ & $64.3 \%$ & $54.1 \%$ & $55.3 \%$ & $56.6 \%$ & $66.4 \%$ & $70.2 \%$ & $61.5 \%$ \\
\hline & & Count & 10 & 34 & 240 & 210 & 169 & 129 & 792 \\
\hline & & $\%$ within Previous & & & & & & & \\
\hline & & $\begin{array}{l}\text { experience with } \\
\text { other ISP }\end{array}$ & $1.3 \%$ & $4.3 \%$ & $30.3 \%$ & $26.5 \%$ & $21.3 \%$ & $16.3 \%$ & $100.0 \%$ \\
\hline & & $\begin{array}{l}\% \text { within Household } \\
\text { monthly income }\end{array}$ & $35.7 \%$ & $45.9 \%$ & $44.7 \%$ & $43.4 \%$ & $33.6 \%$ & $29.8 \%$ & $38.5 \%$ \\
\hline \multirow{3}{*}{ Total } & & Count & 28 & 74 & 537 & 484 & 503 & 433 & 2059 \\
\hline & & $\begin{array}{l}\% \text { within Previous } \\
\text { experience with } \\
\text { other ISP }\end{array}$ & $1.4 \%$ & $3.6 \%$ & $26.1 \%$ & $23.5 \%$ & $24.4 \%$ & $21.0 \%$ & $100.0 \%$ \\
\hline & & $\begin{array}{l}\% \text { within Household } \\
\text { monthly income }\end{array}$ & $100.0 \%$ & $100.0 \%$ & $100.0 \%$ & $100.0 \%$ & $100.0 \%$ & $100.0 \%$ & $100.0 \%$ \\
\hline
\end{tabular}

Note: Chi-square $=34.388, \mathrm{df}=5, \mathrm{p}<0.001$, Cramer's V $=0.129$.

\section{Reasons for switching versus age}

No noticeable difference was found among age groups in terms of their reasons for switching. It can be seen that age did not contribute to the respondents' motivation for switching and this is illustrated in Table 3.

Table 3: Reasons for Switching versus Age

\begin{tabular}{|c|c|c|c|c|c|c|c|}
\hline & & & \multicolumn{4}{|c|}{ Age group } & \multirow[t]{2}{*}{ Total } \\
\hline & & & $18-28$ & $29-38$ & $39-49$ & $\begin{array}{c}50 \text { and } \\
\text { above }\end{array}$ & \\
\hline \multirow{18}{*}{$\begin{array}{l}\text { easons for } \\
\text { switching }\end{array}$} & \multirow{4}{*}{$\begin{array}{l}\text { Less } \\
\text { promotional } \\
\text { package }\end{array}$} & Count & 101 & 192 & 112 & 69 & 474 \\
\hline & & $\%$ within Reasons & $21.3 \%$ & $40.5 \%$ & $23.6 \%$ & $14.6 \%$ & \\
\hline & & $\%$ within Age & $39.0 \%$ & $38.4 \%$ & $35.6 \%$ & $35.8 \%$ & \\
\hline & & $\%$ of Total & $8.0 \%$ & $15.2 \%$ & $8.8 \%$ & $5.4 \%$ & $37.4 \%$ \\
\hline & \multirow{4}{*}{$\begin{array}{l}\text { Poor Internet } \\
\text { service } \\
\text { performance }\end{array}$} & Count & 111 & 238 & 130 & 77 & 556 \\
\hline & & $\%$ within Reasons & $20.0 \%$ & $42.8 \%$ & $23.4 \%$ & $13.8 \%$ & \\
\hline & & $\%$ within Age & $42.9 \%$ & $47.6 \%$ & $41.3 \%$ & $39.9 \%$ & \\
\hline & & $\%$ of Total & $8.8 \%$ & $18.8 \%$ & $10.3 \%$ & $6.1 \%$ & $43.9 \%$ \\
\hline & \multirow{4}{*}{ High price } & Count & 59 & 136 & 82 & 37 & 314 \\
\hline & & $\%$ within Reasons & $18.8 \%$ & $43.3 \%$ & $26.1 \%$ & $11.8 \%$ & \\
\hline & & $\%$ within Age & $22.8 \%$ & $27.2 \%$ & $26.0 \%$ & $19.2 \%$ & \\
\hline & & $\%$ of Total & $4.7 \%$ & $10.7 \%$ & $6.5 \%$ & $2.9 \%$ & $24.8 \%$ \\
\hline & \multirow{4}{*}{$\begin{array}{l}\text { Poor } \\
\text { customer } \\
\text { service }\end{array}$} & Count & 110 & 232 & 131 & 73 & 546 \\
\hline & & $\%$ within Reasons & $20.1 \%$ & $42.5 \%$ & $24.0 \%$ & $13.4 \%$ & \\
\hline & & $\%$ within Age & $42.5 \%$ & $46.4 \%$ & $41.6 \%$ & $37.8 \%$ & \\
\hline & & $\%$ of Total & $8.7 \%$ & $18.3 \%$ & $10.3 \%$ & $5.8 \%$ & $43.1 \%$ \\
\hline & \multirow{2}{*}{ Other reason } & Count & 63 & 114 & 77 & 46 & 300 \\
\hline & & $\%$ within Reasons & $21.0 \%$ & $38.0 \%$ & $25.7 \%$ & $15.3 \%$ & \\
\hline
\end{tabular}


Table 3: Reasons for Switching versus Age (cont'd)

\begin{tabular}{ll|c|c|c|c|c} 
& \% within Age & $24.3 \%$ & $22.8 \%$ & $24.4 \%$ & $23.8 \%$ & \\
\multirow{4}{*}{ Total } & \% of Total & $5.0 \%$ & $9.0 \%$ & $6.1 \%$ & $3.6 \%$ & $23.7 \%$ \\
& Count & 259 & 500 & 315 & 193 & 1267 \\
& \% of Total & $20.4 \%$ & $39.5 \%$ & $24.9 \%$ & $15.2 \%$ & $100.0 \%$ \\
\hline
\end{tabular}

\section{Reasons for switching versus household income}

Table 4 depicts the relationship between monthly household income and reasons for switching. A significantly high percentage of respondents who earned less than 5000 baht selected poor Internet service performance as their motivation for switching service providers. In the under 5,000 baht group of respondents, 61.1 per cent selected poor Internet performance as their reason for switching, whereas this figure only ranged from 32.5 per cent to 47.3 percent for other income groups. On the other hand, high price and less attractive promotional packages were the main reasons among the 5000 to 10,000 baht income group (45 per cent and 42.5 per cent respectively). Based on the survey results, it seems that the low-income group was sensitive to the value for money aspect.

Table 4: Reasons for Switching versus Household Income

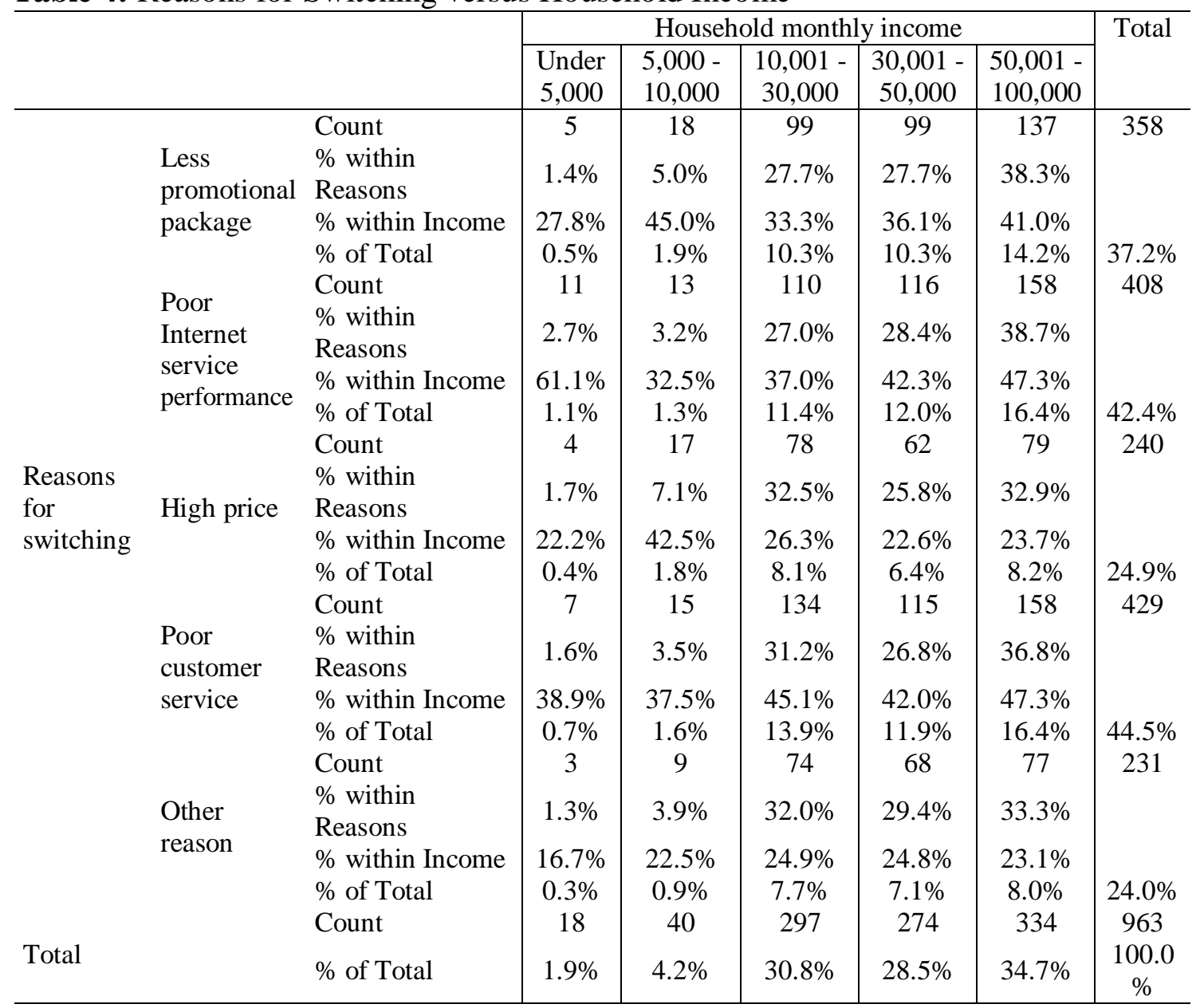




\section{Discussion}

The results indicate that customers tend to rely heavily on the Internet, supporting Thaichon, Lobo, Prentice and Quach (2014). In addition, a majority of respondents in the study had experience switching from other ISPs. This study splits the sample into four groups based on their age: 18-28 years, 29-39 years, 39-49 years and 50 years or over. With regards to switching experience, respondents in the 18-28 age group had less switching experience compared to the other groups. The highest churn rate was among those aged over 50. It appears that age was a determinant of switching intention (Shin and Kim, 2008). However, the percentage of switchers across other age groups varies only slightly. In addition, no noticeable differences were found among age groups in terms of the reasons for their switching. Therefore, it is likely that age did not contribute to the respondents' motivation for switching.

There were five groups with different levels of monthly household income: less than 5,000 baht; 5,000 to 10,000 baht; 10,001 to 30,000 baht; 30,001 to 50,000 baht; 50,001 to 100,000 baht; and over 100,000 baht per month. The results demonstrate that there is a relationship between income and switching experience, consistent with the findings of Kim and Yoon (2004). Apart from the group with household income of less than 5,000 baht, it appears that higher household income is associated with a greater likelihood to switch providers. With regard to reasons for switching, customers with higher income are more likely to choose poor Internet service performance as the main reason to switch. Customer service was also chosen as a reason to switch by a large percentage of higher income groups, as compared to the lower income ones. In addition, high price and fewer promotional packages are popular reasons for switching among groups with the lowest levels of household income. This suggests that low income groups are relatively concerned about value for money compared to higher income groups, who pay more attention to service performance and customer support.In other words, demographic factors such as income and age can predict customer behavior, and can be indicator of customer loyalty (Yang and Peterson, 2004).

\section{Managerial implications}

The telecommunications industry has witnessed high switching rates. Many companies try to acquire new customers through price competition, which might lead to a vulnerable and imbalanced market where smaller companies with low capital cannot compete against major corporations (Buil et al., 2013). Such competition can also diminish the firms' performance and services infrastructure. This study presents a solution to this issue by investigating customer behaviour with a view to achieving sustainable development of the telecommunications industry as a whole.

By categorizing customers into age groups and income level, service providers can create effective marketing strategies for each segment. Today, companies face costly challenges relating to customer acquisition (Abdolvand et al., 2006). Recruiting new customers does not guarantee long-term success for a company, especially when that company cannot retain those customers (Shirin and Puth, 2011). Therefore, these authors suggest that it is important for companies to make effort in increasing customer retention. As it was found that higher income and older customers is more 
likely to switch, ISPs should tailor their approach to these groups. For example, service performance appears to be the dominant reason of switching for customers with high income. A special package with fast and reliable Internet speed could be a good option to promote to this target market. On the other hand, value for money through promotional offers is more likely to appeal to lower income group. Moreover, the number of heavy Internet users are increasing, which present both opportunities and challenges for ISPs as this segment could have very different characteristics and specific requirement (Thaichon, Lobo, Prentice and Quach, 2014).

The study strongly urges ISPs to study their customers and build a long-term relationship with their existing customers. By doing that, ISPs will be able to reduce the current issues relating to customer switching in the home ISP in Thailand, as well as in other countries that have similar demographic profiles.Loyal customers are usually less expensive to serve because of their familiarity with the processes involved in purchasing and using the service. They require less training and less assistance (Mathur, 2011). Jandaghi et al. (2011) report that customer acquisition often costs more than customer retention. Research conducted by Mathur (2011) confirms that, in general, service providers need to spend about four times more resources to attract new customers than to maintain existing loyal customers.For instance, Erevelles et al. (2003) demonstrate that as the Internet services market matures, ISPs that pay attention to building an effective relationship with customers will have a competitive advantage in the marketplace. From the buyers' perspective, customers are likely to look for an ongoing relationship with the service provider to reduce risk and uncertainty. This view has been supported by several researchers, including Lovelock (1983); Patterson and Smith (2001) and Shani and Chalasani (1992).

\section{Conclusion and Future research directions}

This research aims to explore the characteristics and perceptions of Internet Service Provider' customers in order to provide a general picture of ISP subscribers and enable more customer-focused market strategies. Data was obtained from 2,059 Internet users in all the regions of Thailand via an online survey. Although it appears that the switching experience was highly related to age, result shows that no noticeable differences were found among age groups in terms of the reasons for their switching. Therefore, it is likely that age did not contribute to the respondents' motivation for switching. Additionally,with regard to reasons for switching, customers with higher income are more likely to choose poor Internet service performance as the main reason to switch. Customer service was also chosen as a reason to switch by a large percentage of higher income groups, as compared to the lower income ones. In addition, high price and fewer promotional packages are popular reasons for switching among groups with the lowest levels of household income. This knowledge will assist ISPs in understanding their customers better and by doing that, the companies will be able to increase customer retention while decreasing switching rates which have been a serious concern in the ISP industry.

There are several limitations of this study. Firstly, this study was empirically conducted using data of ISP customers in Thailand which could be different from customers in other service industries as well as in other cultures. Future research should be conducted to test the generalisability of this model in other contexts such as 
Vietnam, Cambodia and Burma. Secondly, a longitudinal study of ISP's customers should be carried out to determine the changing patterns of customers' needs and desires. Thirdly, other determinants of switching and loyalty could be included in future studies to explore a more complete picture of ISP customer behaviour.

\section{References}

Abdolvand, N., Charkari, M., and Mohammadi, R., (2006), "Technical model for improving customer loyalty with m-commerce: mobile service providers", International Journal on Computer Science and Information Systems, vol. 1, no. 2, pp. 50-62.

Buil, I., de Chernatony, L., and Martínez, E., (2013), "Examining the role of advertising and sales promotions in brand equity creation", Journal of Business Research, vol. 66, pp. $115-22$.

Butt, M. M., and de Run, E. C., (2009), "Modeling customer satisfaction in cellular phone services", Jurnal Kemanusiaan bil, vol. 13.

CIA (2013), "The world factbook", Retrieved 1st August, 2013, from https://www.cia.gov/library/publications/the-world-factbook/geos/th.html

Erevelles, S., Srinivasan, S. and Rangel, S., (2003), "Consumer Satisfaction of Internet Service Providers: A Process Based Approach", Journal of Information Technology and Management, vol. 4, no. 2, pp. 69-89.

Feeny, A., and Vongpatanasin, T., (1996), "Retailing in Thailand", International Journal of Retail \& Distribution Management, vol. 24, no. 8, pp. 38-45.

IWS (2013), "Asia Marketing Research, Internet Usage, Population Statistics and Facebook Information", Retrieved 4th November, 2013, from http://www.internetworldstats.com/asia.htm

Jandaghi, G., Mehranjani, N., Seresht, N., and Mokhles, A., (2011), "Studying The Effect Of Brand Loyalty On Customer Service In Kerman Asia Insurance Company", Australian Journal of Business and Management Research, vol. 1, no. 6, pp. 152-8.

Kim, H. S., and Yoon, C. H., (2004), "Determinants of subscriber churn and customer loyalty in the Korean mobile telephony market", Telecommunications Policy, vol. 28, no. 9, pp. 751-765.

Kotler, P., (2003), Marketing insights from A to Z: 80 concepts every manager needs to know, Hoboken, N.J.: John Wiley \& Sons.

Lekagul, A., (2002), Toward Preservation of the Traditional Marketplace: A Preference Study of Traditional and Modern Shopping Environments in Bangkok, Thailand, Bangkok, Thailand: Virginia Polytechnic Institute and State University.

Lovelock, C. H., (1983), "Classifying services to gain strategic marketing insights", Journal of Marketing, vol. 47, no. 3, pp. 9-20.

Lovelock, C. H., Wirtz, J., Keh, H. T., and Lu, X., (2002), Services marketing in Asia: managing people, technology, and strategy: Prentice Hall.

Magin, S., Algesheimer, R., Huber, F., and Herrmann, A., (2003), The impact of brand personality and customer satisfaction on customer's loyalty: theoretical approach and findings of a causal analytical study in the sector of internet service providers, Electronic Markets, vol. 13, no. 4, pp. 294-308.

Mathur, A., (2011), "An Empirical Evaluation of the Impact of Services Quality on Customer Loyalty at Customer Care Centre-A Case Study of Customer Service in Telecom Sector at Jodhpur", International Journal of Management and Tourism, vol. 19, no. 1, pp. 106-21.

Michael, R. S., (2001), Crosstabulation \& Chi square. Bloomington, IN: Indiana University.

NECTEC (2014), "Internet User and Statistics in Thailand", Retrieved 1st August, 2014, from http://internet.nectec.or.th/webstats/home.iir?Sec=home

Nielson (2013), "Australian Connected Consumers Report", 02/03/2014, from http://www.nielsen.com/content/dam/corporate/au/en/reports/2013/australianconnected-consumers-flyer-march-2013.pdf 
Patterson, P. G., and Smith, T., (2001), "Modeling relationship strength across service types in a south-east Asian context", International Journal of Service Industry Management, vol. 12, no. 2, pp. 90-113.

Schiffman, G., and Kanuk, L., (1997), Consumer Behaviour, Upper Saddel River, New Jersey: A Simon \& Schuster Company.

Silayoi, P., and Speece, M., (2007), "The importance of packaging attributes: a conjoint analyis approach", European Journal of Marketing, vol. 41, no. 11/12, pp. 1495-1517.

Simsim, M. T., (2011), "Internet usage and user preferences in Saudi Arabia", Journal of King Saud University-Engineering Sciences, vol. 23, no. 2, pp. 101-107.

Shani, D., and Chalasani, S., (1992), "Exploiting Niches Using Relationship Marketing", Journal of Consumer Marketing, vol. 9, no. 3, pp. 33 - 42.

Shin, D. H., and Kim, W. Y., (2008), "Forecasting customer switching intention in mobile service: An exploratory study of predictive factors in mobile number portability", Technological Forecasting and Social Change, vol. 75, no. 6, pp. 854-874.

Shirin, A., and Puth, G., (2011), "Customer satisfaction, brand trust and variety seeking as determinants of brand loyalty", African Journal of Business Management, vol. 5, pp. $11899-915$.

Songpradit, C., (2005), "The marketing factors affecting consumers' purchasing decision of direct-sale cosmetics in Pranakornsri Ayuttaya province", Management Science Review, vol.8, no. 8, pp. 81-85.

Srihirun, P., (2011), "Telecommunications in Thailand", from http://www.itu.int/ITUD/asp /CMS/Events/2011/ITU-ADB/FinalWorkshop/ Thailand-S2.pdf

Sukato, N., and Elsey, B., (2009), "A model of male consumer behaviour in buying skin care products in Thailand", ABAC Journal, vol. 29, no. 1, pp. 39-52.

Teo, T. S. H., and Tan, M., (1998), "An Empirical Study of Adopters and Non-Adopters of the Internet in Singapore", Information and Management, vol. 34, pp. 339-345.

Thaichon, P., Lobo, A., and Mitsis, A., (2012), "Investigating the antecedents to loyalty of Internet service providers in Thailand: Developing a conceptual model", Paper presented at the Australian and New Zealand Marketing Academy Conference, Adelaide, Australia.

Thaichon, P., Lobo, A., and Mitsis, A., (2014), "An Empirical Model of Home Internet Services Quality in Thailand", Asia Pacific Journal of Marketing and Logistics, vol. 26, no. 2, pp. 190-210.

Thaichon, P., Lobo, A., Prentice, C., and Quach, T. N., (2014), "The development of service quality dimensions for Internet Service Providers: retaining customers of different usage patterns", Journal of Retailing and Consumer Services, vol. 21, no. 6, pp.10471058 .

Thaichon, P., and Quach, T. N., (2013), "Integrated marketing communications and their influences on brand loyalty: A Thai perspective", International Journal of Studies in Thai Business, Society and Culture, vol. 2, no. 1, pp. 55-79.

Thananuraksakul, S., (2007), Factors Affecting Online Shopping Behaviour: A Study of Thai Consumers, University of South Australia.

Trkman, P., Jerman-Blažič, B., and Turk, T., (2008), "Factors of broadband development and the design of a strategic policy framework", Telecommunications Policy, vol. 32, no. 2, pp. 101-115.

Wahab, S., Zahari, A., Momani, K., and Nor, N., (2011), "The influence of perceived privacy on customer loyalty in mobile phone services: An Empirical Research in Jordan", International Journal of Computer Science Issues, vol. 8, no. 2.

Webster, C., (2000), "Is spousal decision making a culturally situated phenomenon? " Psychology \& Marketing, vol. 17, no. 12, pp. 1035-1058.

Yang, Z., and Peterson, R. T., (2004), "Customer perceived value, satisfaction, and loyalty: The role of switching costs", Psychology \& Marketing, vol. 21, no. 10, pp. 799-822. 